\title{
Faktor-faktor Yang Mempengaruhi Penawaran Kopra
}

\author{
Ardiansyah 1), Abdulrahim Maruwae ${ }^{2)}$ Meyko Panigoro ${ }^{3)}$ Radia Hafid ${ }^{4)}$ \\ 1)2),344)Dosen Fakultas Ekonomi, Universitas Negeri Gorontalo \\ ardiansyah@gmail.com
}

\begin{abstract}
This study aims to determine the magnitude of the effect of Price (X1) and Distribution Costs (X2), both simultaneously and partially on the Copra Supply (Y) in Bontomatene District, Selayar Islands Regency. The variables in this study consisted of the independent variable (independent variable), namely Price. and distribution costs while the dependent variable (dependent variable) in this study is the Copra Offer (Y). The population in this study were 28 copra traders living in Bontomatene District, Selayar Islands Regency. Data collection in this study used observation, interview and documentation techniques, while the analysis used was multiple linear regression analysis. The results showed that the supply factor was in the form of Price and distribution costs simultaneously have a positive and significant effect on copra supply in Bontomatene District, Selayar Islands Regency. And a partial analysis found that the relationship between price $(X 1)$ and distribution costs $(X 2)$ has a positive and significant effect on copra supply (Y).
\end{abstract}

Keyword: copra supply, price, costs

\section{Pendahuluan}

Industri kecil dan industri menengah dianggap memiliki peluang yang cukup besar dalam mengurangi permasalahan ekonomi karena keberadaan industri kecil dan menengah dapat menciptakan lapangan kerja baru yang secara langsung dapat menyerap angkatan kerja secara otomatis jumlah pengangguran akan berkurang dan pendapatan masyarakat akan meningkat(Haris 2008; Saragih 2018). Salah satu bidang dalam sektor industri yang termasuk industri kecil yang ada di kabupaten kepulauan selayar adalah industri pengolahan buah kelapa (kopra) yang dikelola dengan skala kecil dan menggunakan tenaga kerja dari anggota keluarga sendiri. Beberapa masyarakat memilki kebun kelapa dan kebayakan dari mereka mengolah kelapanya sendiri menjadi kopra. Ada 120 petani kopra yang memiliki perkebunan monokultur di daerah Bontomatene. Pohon kelapa tumbuh hampir di seluruh kepulauan Selayar, dari kawasan pantai sampai daerah pelosok sebagai ptanaman perkebunan rakyat. Hal ini menyebabkan kopra merupakan salah satu produk unggulan bagi Kabupaten Kepulauan Selayar. Setiap Kecamatan di Kabupaten Kepulauan Selayar memberikan sumbangsih produksi kopra.

Salah satu daerah penghasil kopra di Kabupaten Kepulauan Selayar adalah Kecamatan Bontomatene. Kecamatan Bontomatene merupakan salah satu penghasil kopra terbesar kedua setelah Kecamatan Bontomanai. Untuk mendukung proses pemasaran 
khususnya di Daerah Kecamatan Bontomatene Kabupaten Kepulaun selayar maka di perlukan suatu proses globalisasi untuk bisa memasarkan hasil industri kopra agar dapat menyatukan pangsa pasar lokal, interlokal maupun pangsa pasar internasional. Besarnya peluang perdagangan di suatu daerah sangat membantu mobilitas daerah tersebut. Daerah kecamatan bontomatene Kabupaten kepulauan selayar selaku daerah otonom harus dapat meningkatkan pendapatan daerahnya. Salah satu kegiatan ekonomi peningkatan pendapatan daerah adalah kegiatan perdagangan hasil pengolahan indusri perkebunannya berupa kopra.

Penawaran merupakan suatu bagian kegiatan perdagangan yang dilakukan produsen untuk menawarkan jumlah barang pada berbagai tingkat harga (Kasdi 2016). Proses ini merupakan suatu kegiatan yang dilakukan oleh lembaga-lembaga tataniaga, seperti agen, pedagang pengumpul, pedagang besar, pedagang pengecer, serta industri pengolahan dan sebagainya.

Perkembangan perdagangan kopra kecamatan bontomatene tidak terlepas dari faktor pendukung dan faktor penghambat. Faktor pendukung antara lain adanya kekayaan sumber daya alam, tenaga kerja yang murah, pertumbuhan. ekonomi yang baik dan faktor pendukung lainnya. Sedangkan faktor penghambat yaitu kopra sebagai komoditi perdagangan karena persaingan mutu, Pengoplosan dengan cara mencampur kopra dengan bahan lain yang mengakibatkan mutu berubah pula alias anjlok. Kopra juga sangat dipengaruhi oleh fluktuasi harga. Keitidakstabilan harga kopra ini membawa berbagai akibat terhadap produsen dan juga konsumen kopra.

\section{Kajian Teori}

\section{Penawaran}

Penawaran adalah sejumlah barang atau jasa yang ditawarkan oleh penjual pada berbagai tingkat harga dan dalam waktu tertentu, misal per hari, per bulan dan per tahun (Fattach 2017). Jumlah komoditas yang akan dijual oleh penjual disebut kuantitas yang ditawarkan (quantity supplied) yang merupakan arus kontinu per satuan waktu. Jumlah yang ditawarkan bisa berbeda dengan jumlah yang benarbenar dijual. Bisa saja jumlah yang ditawarkan yang benar-benar terjual.

Penawaran merupakan sejumlah barang yang ditawarkan untuk dijual pada berbagai tingkat harga dalam suatu pasar pada waktu tertentu. Dari pengertian tersebut menunjukkan bahwa penjual akan menjual barangnya sejumlah tertentu untuk masing-masing tingkat harga tertentu. Pada saat harga rendah, maka ia hanya menjual sedikit sebab takut rugi, tetapi pada saat harga naik maka jumlah barang yang dijual pun banyak sebab akan memperoleh keuntungan. Penawaran barang tersebut terjadi pada pasar tertentu dan waktu yang tertentu pula, artinya pada pasar yang berbeda dan waktu yang berbeda, maka jumlah barang yang ditawarkan pun kemungkinan berbeda pula.

\section{Harga}

Dalam berbagai macam teori yang terdapat pada literatur ekonomi disebutkan bahwa faktor utama yang 
mempengaruhi penawaran akan suatu barang adalah harga barang itu sendiri. Secara umum, harga diartikan sebagai nilai barang yang ditentukan atau dirupakan dengan uang.

Harga merupakan sejumlah

uang yang dibutuhkan untuk mendapat sejumlah kombinasi dari barang beserta pelayanannya (Barus, Lubis, and Ayu 2013). kebijakan mengenai harga sifatnya hanya sementara, berarti produsen harus mengikuti perkembangan harga di pasar dan harus mengetahui posisi perusahaan dalam situasi pasar secara keseluruhan.

Dari sudut pandang konsumen, harga merupakan sejumlah uang yang dibebankan atas suatu produk atau jas, atau jumlah dari nilai yang ditukar konsumen atas manfaat karena memiliki atau menggunakan produk atau jasa tersebut(Amstrong 2001).

Pada tingkat harga tertentu, Apabila harga barang yang ditawarkan mengalami kenaikan, maka jumlah barang yang ditawarkan juga akan meningkat. Sebaliknya jika barang yang ditawarkan turun jumlah barang yang ditawarkan penjual juga akan turun (Habibah 2016; Pujiati 2020b; 2020a).

\section{Biaya Faktor Produksi}

Biaya produksi berkaitan dengan biaya yang digunakan dalam proses produksi, seperti biaya untuk membeli bahan baku, biaya untuk gaji pegawai, biaya untuk bahan-bahan penolong, dan sebagainya. Biaya tenaga kerja langsung diperlakukan sebagai elemen biaya variabel. Sehingga dalam konsep penentuan harga pokok variabel, biaya tenaga kerja langsung adalah elemen biaya produksi (Sunarto and 2003, n.d.; Menengah, Cita, and Khas 2017; Budiman, Ilat, and Mawikere 2019).

\section{Metode Penelitian}

Penelitian ini menganalisis faktor-faktor yang mempengaruhi penawaran kopra di Kecamatan Bontomatene Kabupaten Kepulauan Selayar. Dengan demikian yang menjadi variabel bebas dalam penelitian ini adalah harga kopra (X1) dan biaya distribusi (X2) sedangkan variabel terikatnya adalah penawaran kopra (Y) di Kabupaten Kepulauan Selayar.

Definisi Operasional Variabel ini diperlukan sebagai batasan operasional masing-masing variabel yang diteliti untuk memperjelas arah dan ruang lingkup variabel penelitian. Adapun batasan operasional masing-masing variabel yang di maksud adalah:

1. Harga kopra adalah nilai jual kopra yang diukur dengan satuan rupiah (Rp).

2. Biaya distribusi adalah biaya yang dikeluarkan oleh pedagang pengumpul berupa yaitu biaya tenaga kerja, biaya angkut, biaya pembelian karung, biaya penyusutan kopra ,biaya pemeliharaan gudang dan biaya pembelian kopra dari petani yang diukur dengan satuan rupiah (Rp).

3. Penawaran adalah jumlah barang yang ditawarkan oleh pedagang pengumpul terhadap pedagang besar kopra di Kecamatan Bontomatene Kabupaten Kepulauan Selayar 
pada berbagai tingkat harga yang diukur dengan satuan $\mathrm{Kg}$.

Populasi dalam penelitian ini adalah seluruh pedagang kopra di Kecamatan Bontomatene Kabupaten Kepulauan Selayar sebanyak 28 orang. Sampel merupakan bagian dari populasi yang diteliti, karena populasi dalam penelitian ini jumlah sedikit yakni hanya berjumlah 28 orang maka dapat digunakan penarikan sampel jenuh yakni populasi digunakan sabagai sampel.

Dalam penelitian digunakan teknik pengumpulan data berikut observasi, wawancara, dan dokumentasi.

1. Observasi merupakan pengumpulan data dengan melalui pengamatan langsung terhadap proses aktivitas operasional pedagang kopra di Kecamatan Bontomatene Kabupaten Kepulaun Selayar guna memperoleh gambaran umum mengenai objek penelitian.

2. Dokumentasi yakni teknik ini digunakan untuk memperoleh data yang berkaitan dengan objek penelitian yaitu mengumpulkan literaturliteratur yang berkaitan dengan data yang dibutuhkan dalam proses penelitian ini.

3. Wawancara merupakan pengumpulan data dengan cara mengajukan pertanyaan kepada setiap responden secara langsung dengan metode tanya jawab kepada para pedagang kopra di Kecamatan
Bontomatene Kabupaten

Kepulaun Selayar.

Analisis data dilakukan untuk mengetahui faktor-faktor yang mempengaruhi penawaran kopra di Kecamatan Bontomatene Kabupaten Kepulauan Selayar maka digunakan statistik induksi regresi linear berganda menurut Soegyarto (2004:258) sebagai berikut :

$$
Y=b o+b 1 X 1+b 2 X 2+e
$$

Dimana :

$\mathrm{Y}=$ Tingkat Penawar

b0 = Intersep/konstan

b1, b2, =Koefesien regresi parsial untuk $\mathrm{X} 1, \mathrm{X} 2$

$\mathrm{X} 1=$ Harga Kopra

$\mathrm{X} 2=$ biaya distribusi

e $\quad=$ Koefisien eror

Uji F

Uji F dilakukan untuk mengatahui variabel bebas secara bersama-sama terhadap variabel terikat rumusan hipotesis yang di uji:

Ho $: b 1=b 2=0$, berarti secara bersamasama tidak ada pengaruh variable bebas terhadap variable terikat

Ha : b1 $\neq b 2 \neq 0$, berarti secara bersamasama ada pengaruh variable bebas terhadap variable terikat.

bila F hitung > F tabel maka Ho ditolak dan Ha diterima, semua variabel bebas secara bersama-sama merupakan penjelas yang signifikan terhadap variabel terikat.bila $\mathrm{F}$ hitung $<\mathrm{F}$ tabel maka Ho diterima dan Ha ditolak, semua variabel bebas secara bersamasama bukan merupakan variabel penjelas yang signifikan terhadap variabel terikat. 


\section{Uji $\mathbf{t}$}

Uji $t$ pada dasarnya menunjukkan seberapa jauh pengaruh satu variable bebas secara individual dalam menerangkan variasi variable terikat. Formula hipotesisnya adalah

Ho : bi $=0$, artinya variable bebas bukan merupakan penjelas yang signifikan terhadap variable terikat

Ha : bi $\neq 0$, artinya variable bebas merupakan penjelas yang signifikan terhadap variable terikat.

Untuk mengatahui kebenaran hipotesis digunakan kriteria bila $t$ hitung $>\mathrm{t}$ tabel maka Ho ditolak dan $\mathrm{Ha}$ diterma artinya ada pengaruh antara variable bebas terhadap variabel terikat. Begitu pula sebaliknya bila $\mathrm{t}$ hitung $<\mathrm{t}$ tabel maka menerima Ho dan menoloak Ha artinya tidak ada pengaruh antara variabel bebas terhadap variabel terikat.

\section{Hasil Dan Pembahasan}

\section{Karakteristik Responden}

Berdasarkan hasil penelitian yang digunakan dengan menggunakan teknik wawancara dengan menunjuk semua pedagang yang terdapat di Kecamatan Bontomatene Kabupaten Kepulauan Selayar yang berjumlah 28 orang usaha dan dibagi berdasarkan karakteristik sebagai berikut:

\section{Tingkat Umur}

Tingkat umur merupakan salah salah satu faktor yang mempengaruhi tingkat produktivitas usaha. Pedangang yang berada pada umur produktif memiliki kondisi optimal untuk melakukan kegiatan dalam upaya peningkatan produksi. Untuk lebih jelasnya mengenai karakteistik responden menurut tingkat umur dapat dilihat pada tabel 1, sebagai berikut :

Tabel 1 : Distribusi responden menurut kelompok umur

\begin{tabular}{lcc}
\hline Tingka Umur & Frekuensi & Persentase $\mathbf{( \% )}$ \\
\hline $30-39$ tahun & 9 & 32,13 \\
$40-49$ tahun & 16 & 57,12 \\
$50-59$ tahun & 3 & 10,75 \\
\hline Total & $\mathbf{2 8}$ & $\mathbf{1 0 0}$ \\
\hline
\end{tabular}

Sumber : Hasil Pengolahan Data Primer, 2021

Distribusi responden menurut tingkat umur pada tabel 8 dapat dilihat dalam 3 tingkatan. Jumlah responden yang berumur 30-39 tahun sebanyak 9 orang atau sebesar $32,13 \%$, umur 40-49 sebanyak 16 orang atau $57,12 \%$, umur 50-59 tahun sebanyak 3 orang atau 10,75 $\%$.

\section{Tingkat Pendidikan}

Tingkat pendidikan seorang pedagang merupakan salah satu indikator kegiatan sosial ekonomi. Semakin tinggi tingkat pendidikan seseorang maka kemungkinan tingkat pola pikir yang dimilikinya untuk mengembangkan usahanya juga lebih luas dan mudah menerima inovasiinovasi atau perubahan yang terjadi dalam struktur masyarakat dalam suatu 
wilayah. Distribusi responden menurut tingkat pendidikan di Kecamatan
Bontomatene Kabupaten Kepulauan

Selayar dapat dilihat pada tabel berikut.

Tabel 2 : Distribusi responden menurut tingkat pendidikan

\begin{tabular}{llll}
\hline No & Tingkat Pendidikan & $\begin{array}{l}\text { Frekuensi } \\
\text { (Orang) }\end{array}$ & $\begin{array}{l}\text { Persentase } \\
\mathbf{( \% )}\end{array}$ \\
\hline 1. & Tidak Tamat SD & - & - \\
2. & Tamat SD & - & - \\
3. & Tamat SMP & 2 & 7,14 \\
4. & Tamat SMA & 22 & 78,58 \\
5. & S1 & 4 & 14,28 \\
\hline & Jumlah & 28 & $100 \%$ \\
\hline
\end{tabular}

Sumber: Hasil Pengolahan Data Primer, 2021

Dari tabel dapat dikemukakan bahwa pada umumnya responden telah melalui jenjang pendidikan formal, terlihat pada tabel jumlah responden yang tidak tamat SD dan tamat SD tidak ada, Tamat SMP sebanyak 2 orang atau $7,14 \%$, dan Tamat SMA sebanyak 22 orang atau 78,58 dan perguruan tinggi sebanyak 4 orang atau 14,28. Dari data tersebut penulis menarik kesimpulan bahwa sebagian dari memiliki tingkat pendidikan. Hal ini dapat mempengaruhi tingkat produktifitas dalam pengelolaan usaha berdagan kopra.

Jumlah Tanggungan Keluarga

Analisis sosial ekonomi rumah tangga harus mempertimbangkan jumlah tanggungan keluarga, karena setiap rumah tangga mempunyai beban tanggungan yang berbeda sehingga jumlah tanggungan keluarga harus mendapatkan perhatian dalam analisis ekonomi usaha. Untuk memperoleh gambaran tentang jumlah tanggungan keluarga penjahit seragam sekolah dapat dilihat pada tabel berikut ini:

Tabel 3: Distribusi responden berdasarkan tanggungan keluarga

\begin{tabular}{|c|c|c|}
\hline Jumlah Tanggungan Keluarga & Frekuensi (Orang) & Persentase $(\%)$ \\
\hline $1-2$ & 2 & 7,14 \\
\hline $3-4$ & 5 & 17,85 \\
\hline $5-6$ & 12 & 42,78 \\
\hline $7-8$ & 6 & 21,42 \\
\hline $9-10$ & 3 & 10,81 \\
\hline Total & 28 & 100 \\
\hline
\end{tabular}

Sumber : Pengolahan Data Primer, 2021 
Tabel 3 menunjukkan bahwa pedagan kopra yang memiliki tanggungan keluarga sebanyak 1-2 orang berjumlah 2 pedagan atau 7,14 \%, 3-4 orang tanggungan keluarga berjumlah 5 pedagan atau 17,85 \%, 5-6 orang tanggungan keluarga berjumlah 12 pedagan atau $42,78 \%, 7-8$ orang tanggungan keluarga berjumlah 6 pedagan atau $21,42 \%$, dan 9-10 orang tanggungan keluarga berjumlah 3 pedagan atau $10,81 \%$.

\section{Pengalaman berusaha kopra}

Pengalaman berusaha kopra merupakan salah satu faktor yang berpengaruhi kualitas dan kuantitas produksi usaha seseorang. Pedagang kopra yang mempunyai pengalaman kerja lebih lama diperkirakan akan memiliki kemapuan lebih baik dalam $\begin{array}{lrr}\text { menjalankan kegiatan usahanya } & \\ \text { dibandingkan } & \text { pedagang } & \text { kurang }\end{array}$ berpengalaman. Namun itu bukanlah hal mutlak, karena tidak ada jaminan bahwa pedagang yang berpengalaman yang ditinjau dari lamanya menggeluti usaha tersebut berarti akan lebih baik dari pegusaha yang kurang berpengalaman atau baru mendirikan usaha karena masih terdapat faktorfaktor lain yang bisa mempengaruhi usaha dalam berdagang.Untuk memperoleh gambaran mengenai pengalaman usaha berdagang kopra di Kecamatan Bontomatene Kabupaten Kepulauan Selayar dapat dilihat pada tabel berikut

Tabel 4: Distribusi responden berdasarkan pengalaman berdagang kopra

\begin{tabular}{ccc}
\hline Lama Pengalaman Usaha (Tahun) & Frekuensi (Orang) & Persentase (\%) \\
\hline $1-9$ & 6 & 21,42 \\
$10-19$ & 9 & 32,13 \\
$20-29$ & 13 & 46,45 \\
\hline Total & $\mathbf{2 8}$ & $\mathbf{1 0 0}$ \\
\hline
\end{tabular}

Sumber: Pengolahan Data Primer, 2021

Tabel 4 menunjukkan bahwa jumlah responden menurut lamanya berdagang menunjukkan sebanyak 6 responden atau $21,42 \%$ yang memiliki pengalaman usaha 1-9 tahun, 9 responden atau 32,13 yang memiliki pengalaman usaha 10-19 tahun, dan 13 responden yang memiliki pengalaman usaha 20-29 tahun. Penggunaan Tenaga Kerja Untuk mendukung proses kegiatan distribusi dalam berdagang kopra maka dibutuhkan beberapa tenaga kerja untuk bisa memindahakan kopra dari produsen atau pembuat kopra ke pedagang besar. Klasifikasi responden menurut penggunaan tenaga kera di Kecamatan Bontomatene Kabupaten Kepulauan Selayar dapat di lihat pada tabel 5 . 
Tabel 5 : Distribusi responden berdasarkan penggunaan tenaga kerja padagang

\begin{tabular}{lcc}
\hline Jumlah Tenaga Kerja (jiwa) & Frekuensi & Persentase \% \\
\hline $1-5$ & 4 & 14,28 \\
$6-10$ & 18 & 64,26 \\
$11-20$ & 6 & 21,46
\end{tabular}

\begin{tabular}{lll}
\hline Total & 28 & 100 \\
\hline
\end{tabular}

Sumber: Pengolahan Data Primer, 2021

Tabel menunjukkan bahwa 4 responden atau $14,28 \%$ yang menggunakan 1-5 tenaga kerja, 18 responden atau $64,26 \%$ yang menggunakan 6-10 tenaga kerja, 6 responden atau $21,46 \%$ yang menggunakan 11-20 tenaga kerja,

\section{Pembahasan Hasil Penelitian}

Analisis data dalam Penelitian ini dilakukan dengan menggunakan regresi linera berganda sebagai berikut. $\mathrm{Y}=\mathrm{bo}+\mathrm{b} 1 \mathrm{X} 1+\mathrm{b} 2 \mathrm{X} 2+\mathrm{e}$

Hasil olah data melalui komputer dengan program SPSS 21 Windows menunjukkan nilai $\beta 0, \beta 1$, dan $\beta 2$ yaitu :

$$
\begin{aligned}
& \beta 0=-2063.627 \\
& \beta 1=0,819 \\
& \beta 2=0,00
\end{aligned}
$$

Jika memperhatikan kembali bentuk persamaan setelah menarik logaritma natural dari persamaan regresi linear berganda yaitu :

$$
\begin{aligned}
& \mathrm{Y}=\mathbf{b o}+\mathbf{b} 1 \mathbf{X} \mathbf{1} \mathbf{1 + b} \mathbf{2} \mathbf{X} \mathbf{2}+\mathbf{e} \\
& \mathrm{Y}=-2063.627+0,819 \times 1+0,00 \times 2+\mathrm{e}
\end{aligned}
$$

\section{Uji Keberartian Regresi (Uji-F)}

Untuk mengetahui keberartian koifisien regresi diatas, maka hipotesis uji-F pada tabel analisis varians dengan memperhatikan hipotesis sebagai berikut: $\mathrm{H} 0: \beta 0+\beta 1+\beta 2=0 \mathrm{H} 1$ : sekurang-kurangnya satu nilai $\beta$ tidak sama dengan nol Kriteria pengujian adalah $\mathrm{H} 0$ ditolak atau $\mathrm{H} 1$ diterima, jika nilai Fhitung $\geq$ nilai Ftabel pada signifikansi $\alpha=0,05$ maka H1 diterima dan H0 ditolak. Sebaliknya, jika nilai Fhitung $\leq$ Ftabel, maka H0 diterima. Adapun uji $\mathrm{F}$ yang dimaksud dapat dilihat pada tabel dibawah ini:

Tabel 6. Ringkasan Analisis Varians untuk Regresi Penawaran kopra Terhadap Faktor Penawaran Kopra.

\begin{tabular}{llllll}
\hline $\begin{array}{l}\text { Sumber } \\
\text { varians }\end{array}$ & Df & $\begin{array}{l}\text { Jumlah } \\
\text { Kuadrat }\end{array}$ & $\begin{array}{l}\text { Rata-rata } \\
\text { Kuadrat }\end{array}$ & F & Sign F \\
\hline $\begin{array}{l}\text { Regresi } \\
\text { Residu }\end{array}$ & 2 & $3.362 \mathrm{E} 7$ & $1.681 \mathrm{E} 7$ & 53.001 & 0.000 \\
\hline Total & 25 & 7929212.673 & 317168.507 & & \\
\hline
\end{tabular}

Sumber : Olah Data SPSS, 2021 
Dari tabel diatas, menunjukkan bahwa nilai Fhitung sebesar 53.001 dengan signifikansi 0,000 jauh lebih kecil dari taraf signifikansi yang digunakan dalam penelitian ini yaitu 0,05 (Fhitung sebesar 63,352 > Ftabel sebesar 3,38). Dengan demikian dapat disimpulkan bahwa pengujian hipotesis diatas menolak $\mathrm{H} 0$ atau menerima $\mathrm{H} 1$. Hal ini menunjukkan bahwa harga dan biaya distribusi secara simultan mempunyai pengaruh yang signifikan terhadap penawaran kopra di Kecamatan Bontomatene Kabupaten Kepulauan Selayar

Koefisien determinasi

sebesar 0,809 berarti variabel harga dan biaya distribusi memberi kontribusi 80,9 $\%$ terhadap penawaran kopra, sedangkan sisanya sebesar 19,1 \% dipengaruhi oleh faktor lain yang tidak diperhatikan dalam penelitian ini.

Uji Keberartian Masing-Masing Variabel Bebas (Uji-t)

Selanjutnya untuk mengetahui faktor penawaran mana saja yang mempunyai pengaruh yang bermakna terhadap penawaran kopra di Kecamatan Bontomatene Kabupaten Kepulauan Selayar maka dilakukan uji t. Hipotesis yang digunakan dalam pengujian ini adalah : $\mathrm{H} 0$ : menolak $\beta 1+$ $\beta 2=0$ melawan $\mathrm{H} 1: \neq 0$ dimana $\mathrm{I}(1,2$, Hasil uji $\mathrm{t}$ diperlihatkan dalam tabel berikut ini.

Tabel 7. Uji t Untuk Menghitung masing-masing Faktor Penawaran

\begin{tabular}{llllll}
\hline Variabel & B & SD & Beta & T & Sign T \\
\hline Harga $\left(\mathrm{X}_{1}\right)$ & 0.819 & 0.358 & 0.201 & 2.291 & 0.031 \\
Biayadistribusi $\left(\mathrm{X}_{2}\right)$ & 0.000 & 0.00 & 0.898 & 10.221 & 0,00 \\
\hline constant & -2063.627 & 1290.323 & & -1.599 & 0.122 \\
\hline
\end{tabular}

Sumber : Olah data SPSS, 2021

Berdasarkan tabel diatas, maka dapat dilakukan analisa pengujian sebagai berikut:

\section{Harga}

Berdasarkan tabel 7, dimana nilai $\beta$ sebesar 0,819 hal ini berarti,Harga mempunyai pengaruh positif terhadap penawaran kopra dan nilai $\mathrm{t}$ hitung sebesar 2,291 dengan signifikan T 0,031 dinyatakan jauh lebih kecil dari taraf kepercayaan 0,05 sehingga secara parsial Harga $\left(X_{1}\right)$ mempunyai pengaruh yang signifikan terhadap penawaran kopra, dan nilai koifisien regresinya yaitu 0,819 yang

berarti bahwa setiap kenaikan 1 Rupiah harga akan mengakibatkan kenaikan penawaran kopra sebesar 0,819 Rupiah. Alasanya semakin tinggi harga kopra di pasar akan menyebabkan penawaran kopra mengalami kenaikan.

\section{Biaya distribusi}

Berdasarkan tabel diatas, dimana nilai $\beta$ sebesar 0,00 hal ini berarti, biaya faktor produksi berpengaruh positif terhadap penawaran kopra dan nilai $\mathrm{t}$ hitung sebesar 10,221 dengan signifikan t 0,00 dinyatakan jauh lebih kecil dari taraf signifikan yang digunakan yaitu 0,05. Hal ini akan memberikan indikasi 
bahwa secara parsial biaya distribusi $\left(X_{2}\right)$ mempunyai pengaruh yang signifikan terhadap penawaran kopra. Koefisien regresi sebesar 0.00 menunjukkan bahwa kenaikan sebesar 1 Rupiah biaya distribusi akan mengakibatkan kenaikan penawaran kopra sebesar 0.00 Rupiah.

\section{Kesimpulan}

Berdasarkan hasil penelitian dan pengolahan analisis data, maka dapat ditarik kesimpulan bahwa harga dan biaya distribusi secara simultan berpengaruh positif dan signifikan terhadap penawaran kopra di Kecamatan Bontomatene Kabupaten Kepulauan Selayar. Secara parsial, faktor yang berpengaruh positif dan signifikan terhadap penawaran kopra adalah harga dan biaya distribusi terhadap penawaran kopra di Kecamatan Bontomatene Kabupaten Kepulauan Selayar adalah harga. Hasil analisis data menunjukkan Koefisien determinasi (R2) sebesar 0,809 berarti variabel harga dan biaya distribusi memberi kontribusi 80,9\% terhadap penawaran kopra, sedangkan sisanya sebesar 19,1 \% dipengaruhi oleh faktor lain yang tidak diperhatikan dalam penelitian ini

\section{Daftar Pustaka}

Amstrong, kotler dan. 2001. PrinsipPrinsip Pemasaran. jakarta: erlangga.

Barus, Apriyani, satia Negara Lubis Lubis, and sri Fajar Ayu. 2013. "Analisis Permintaan Dan Penawaran Kedelai Di Sumatera Utara." Journal of Chemical
Information and Modeling 53 (9): 1689-99.

Budiman, Jonathan Julio, Ventje Ilat, and Lidia M. Mawikere. 2019. "Analisis Penentuan Biaya Produksi Dengan Menggunakan Metode Full Costing Untuk Menentukan Harga Jual Pada Pt. Blue Ocean Grace International." Going Concern: Jurnal Riset Akuntansi 14 (1): 122-29. https://doi.org/10.32400/gc.14.1.223 19.2019.

Fattach, An'im. 2017. “TEORI PERMINTAAN DAN

PENAWARAN DALAM

EKONOMI ISLAM." Vol37, No.1/2, II (3): 1-27.

https://ci.nii.ac.jp/naid/40021243259 L.

Habibah, Ummu. 2016. "Pengaruh Kualitas Produk Dan Harga Terhadap Keputusan Pembelian Produk Kosmetik Wardah Di Kota Bangkalan Madura" 1 (1): 31-48.

Haris, A. Numan. 2008. "KEBIJAKAN PENGEMBANGAN INDUSTRI KECIL DAN MENENGAH SEBAGAI UPAYA UNTUK MENGHADAPI ERA PERDAGANGAN BEBAS" XXI (3): 1-6.

Kasdi, Abdurrohman. 2016. "PERMINTAAN DAN PENAWARAN DALAM MEMPENGARUHI PASAR (Studi Kasus Di Pasar Bintoro Demak)." BISNIS: Jurnal Bisnis Dan Manajemen Islam 4 (2): 18. https://doi.org/10.21043/bisnis.v4i2. 2688. 
Menengah, D A N, Jajanan Cita, and Rasa Khas. 2017. "Analisis Perhitungan Biaya Produksi Pada Usaha Mikro, ( Studi Kasus UD.Sari Artha Kue, Kec.Banjar, Kab.Buleleng )." E-Journal S1 Ak 8. Pujiati, Naning. 2020a. "Analisis Penyebab Fluktuasi Harga Barang Pokok Di Pasar Kabupaten 